\title{
Microempreendedorismo e desenvolvimento local em Portalegre/RN: panorama atual
} \author{
Amanda Aquino de França ${ }^{1}$ \\ Stênio Maia Estevam² \\ Boanerges de Freitas Barreto Filho ${ }^{3}$
}

\begin{abstract}
Resumo: O objetivo do trabalho se desdobra em descrever o contexto em que as microempresas estão operando e os papéis que desempenham para o Desenvolvimento Local (DL) de Portalegre/RN, a partir da percepção dos microempreendedores. Realizou-se pesquisa bibliográfica e, compreendendo a importância da percepção dos sujeitos sociais sobre o microempreendedorismo e seus efeitos para o Desenvolvimento Local, foram realizadas entrevistas com os microempreendedores e o responsável pela Sala do Empreendedor. Apurou-se que, em 2019, existiam 293 microempresas com Alvarás de Licenciamento expedidos pelo município de Portalegre/RN, sendo 162 microempresas formalizadas; em face de tal cenário, definiu-se uma amostra de 15\% como bem representativa, chegando-se à quantidade de 25 microempreendedores. Os resultados apontaram que a formalização dos negócios cresceu a partir da legislação do Microempreendedor Individual (MEI), alcançando 55,3\% dos microempreendimentos cadastrados na Junta Comercial do município; quase 65\% indicaram grau de escolaridade de Ensino Médio completo ou maior, sugerindo boas possibilidades para absorverem conhecimentos aplicáveis aos negócios e 100\% dos pesquisados acreditam que seus negócios têm papel relevante para o DL, especialmente pela geração de ocupações e renda. Por outro lado, apurou-se que os microempreendedores não consideram que desfrutem de um ambiente institucional propício ao DL, ressaltando a insuficiência de apoios dos Governos Federal e Estadual e a modesta atuação do Governo Municipal (Setor Público pouco ativo para fomentar os microempreendimentos); não foram identificadas associações e/ou laços de confiança sólidos entre os entrevistados, que pudessem sinalizar a formação de capital social; os negócios geram rendas suficientes apenas para o sustento familiar, apontando baixa capacidade de reinvestimentos para ampliação e/ou incorporação de inovações; enfim, verificou-se que os microempreendedores de Portalegre/RN conseguem garantir condições de vida digna em termos individuais e familiares, mas não desfrutam das condições necessárias para deslanchar o DL.
\end{abstract}

Palavras-chave: Mercado. Microempreendedorismo. Desenvolvimento local.

Resumen: El objetivo del trabajo se desarrolla al describir el contexto en el que operan las microempresas y las funciones que desempeñan para el Desarrollo Local (DL) de Portalegre/RN, basándose en la percepción de los microempresarios. Se llevaron a cabo investigaciones bibliográficas y, entendiendo la importancia de la percepción de los temas sociales sobre el microemprendimiento y sus efectos para el desarrollo local, se realizaron entrevistas con microempresarios y la persona responsable de la Sala del Emprendedor. Se encontró que en 2019 había 293 microempresas con Permisos de Licencia expedidos por el Ayuntamiento, 162 de las cuales eran microempresas formalizadas, definiendo una muestra del 15\% como activo representativo, alcanzaron el número de 25 microempresarios. Los resultados mostraron que la formalización de las empresas surgió de la legislación del Microempresario Individual (MEI) llegando al 55,3\% de las microempresas inscritas en el Consejo Comercial del municipio; casi el 65\% indicó un grado de educación completa o superior, lo que sugiere buenas posibilidades para absorber los conocimientos aplicables a las empresas y; El 100\% de los encuestados cree que sus negocios desempeñan un papel relevante para DL, especialmente mediante la generación de ocupaciones e ingresos. Por otra parte, se constató que los microempresarios no consideran que disfrutan de un entorno institucional propicio para DL, haciendo hincapié en la falta de apoyo de los gobiernos federal y estatal y el modesto desempeño del Gobierno Municipal (Sector Público no activo para promover las microempresas); no se identificaron asociaciones sólidas y/o vínculos de confianza entre los entrevistados que pudieran señalar la formación de capital social; las empresas generan suficiente sustento de ingresos sólo para los medios de vida familiares, lo que apunta a una baja capacidad de reinversión para la expansión y/o la incorporación de innovaciones; Finalmente, se encontró que los microempresarios de Portalegre / RN pueden garantizar condiciones de vida dignas en términos individuales y familiares, pero no disfrutan de las condiciones necesarias para desencadenar el DL.

Palabras claves: Mercado. Microempresario. Desarrollo local.

\footnotetext{
1 Universidade do Estado do Rio Grande do Norte (UERN). Bacharela em Ciências Econômicas. E-mail: amandaqfranca@gmail.com.

${ }^{2}$ Universidade do Estado do Rio Grande do Norte (UERN). Mestre em Planejamento e Dinâmicas Territoriais. Email: steniopinheiromais@hotmail.com.

${ }^{3}$ Universidade do Estado do Rio Grande do Norte (UERN). Mestre em Planejamento e Dinâmicas Territoriais. Professor do Departamento de Economia/UERN.E-mail: boanerges.sms@hotmail.com.
} 


\section{Introdução}

Desde o alvorecer da Revolução Industrial inglesa apreende-se que o sistema capitalista é marcado por transformações tecnológicas, mudanças institucionais e de processos organizacionais, conferindo-lhe grande capacidade de adaptação e superação das dificuldades (crises). À medida que as transformações se aceleram e o processo de globalização cuida da integração de todas as áreas do planeta ampliam-se as discussões sobre os papéis que as distintas localidades poderiam desempenhar na Divisão Territorial do Trabalho.

A dicotomia global-local serviu como pano de fundo para parte da produção acadêmica que ganhou maior exposição no Pós Segunda Guerra Mundial e o mapeamento de experiências bem sucedidas, bem como a identificação dos fatores dos êxitos de algumas áreas em relação a outras, passou a chamar atenção de maior número de pesquisadores e agências internacionais ligadas à Organização das Nações Unidas (ONU) e ao Banco Mundial. Notadamente, a partir da intensificação das migrações, ocorreu a preocupação de analisar os fatores que favoreceriam o estabelecimento da população numa cidade, região, em detrimento de outras (SWINBURN, GOGA, MURPHY, 2006).

Martins (2002) acredita que o DL é resultado da ação humana, posto que procura solucionar problemas do cotidiano e tendo como propósitos a conquista de melhores níveis de bem estar e qualidade de vida para uma determinada comunidade. Ou seja, o intuito diferenciado do DL estaria em estabelecer a importância do papel da comunidade na participação ativa no processo de desenvolvimento.

Verifica-se que as circunstâncias favoráveis ao florescimento e expansão dos negócios passaram a ser salientadas como um elemento desejável para a promoção do DL, isso porque um ambiente propício para os negócios permitiria aos empreendedores, inclusive micro, realizarem seus potenciais inovadores e assim alavancar a economia.

Colocada dessa forma, tem-se que não seria uma causa impossível algumas áreas dos países não desenvolvidos alcançarem níveis mais desejáveis de desenvolvimento. O desejo dos agentes locais para identificação e potenciação dos aspectos favoráveis, bem como a superação das dificuldades, também se apresenta como um importante fator para deslanchar o DL.

Ambiente favorável para a inovação, capital social, capital humano, governança pública, responsabilidade social e ambiental, enfim, um amplo leque de elementos passou a servir como delineadores das perspectivas que se apresentavam (ou não) para que um local conseguisse o desenvolvimento.

Em tal contexto, alçou-se ao protagonismo o papel do empreendedor e do microempreendedor, tanto em países desenvolvidos como em subdesenvolvidos. O DL passou a se configurar como uma condição possível, inclusive para as denominadas cidades pequenas, como é o caso de Portalegre, localizada no interior do Rio Grande do Norte.

O DL, a partir do protagonismo do empreendedorismo e do microempreendedorismo, provavelmente, relaciona-se com a capacidade de adaptação às diferentes realidades, seja no atendimento de nichos mercadológicos a partir da exploração de diferenciais existentes numa determinada área 
(exemplo do turismo), e/ou pelo fato de a própria existência de um ambiente favorável para a inovação e diversificação nos negócios seja capaz de deslanchar o processo.

Mas, em virtude da flexibilidade, diversidade e capacidade adaptativa frente às diferentes possibilidades existentes, outros aspectos também podem ser apontados como motivadores do empreendedorismo. Correndo-se o risco de simplificação demasiada, alguns aspectos podem ser salientados, tais como: o aumento do desemprego e a necessidade de obtenção de uma renda (empreendedorismo por necessidade), a vontade de explorar um dom já existente que, muitas vezes, não é reconhecido num ambiente empresarial tradicional, a realização profissional e o denominado empreendedorismo por oportunidade (MENEZES, QUEIROZ, FEIJÓ, 2017; VALE, CORRÊA, REIS, 2014).

Segundo Baggio e Baggio (2015), o empreendedor se lança ao mercado admitindo os riscos, avaliando e aproveitando as oportunidades, sendo movidos pelo senso de oportunidade, agindo com um espírito inovador e proporcionando estratégias proativas para solucionar problemas.

Já Hespanha (2009) acredita que ocorre uma generalização exageradamente positiva, a partir de certo viés ideológico sobre o papel do empreendedorismo, colocando-se como verdadeira a máxima a assertiva de que o empreendedor sempre teria êxito na aplicação dos recursos. O que acontece, na verdade, é que tal percepção seria induzida pela massificação dos casos de sucesso, dando-se pouca ênfase para os insucessos e para o fato de que nem todos os empreendedores têm a capacidade e a possibilidade de inovarem, de gerenciar com êxito um grande negócio, de produzir em grande quantidade, de dispor um grande montante de recursos e de, por consequência, alcançar elevada lucratividade em seus negócios.

É bem provável que os casos mais numerosos de ações empreendedoras sejam menos glamorosos, mas nem por isso deixam de desempenhar papel importante na economia, especialmente quando se consideram as dificuldades vivenciadas pelos empreendedores que não contam com recursos significativos para iniciarem os negócios.

Considerando a amplitude de abordagens que a temática permite, apresenta-se o conceito de microempreendedorismo que sustenta essa pesquisa. De acordo com Hespanha (2009), o microempreendedorismo é uma especificidade do empreendedorismo com dimensões menores, em que são caracterizados, geralmente, pelo volume financeiro ou pela quantidade de pessoas envolvidas no negócio, em escalas bem mais modestas do que aquela existente nas médias e grandes corporações. Ademais, merece também consideração o papel social, a diminuição do desemprego e da pobreza, fatores que contribuem sensivelmente para a estabilidade social e para o crescimento da economia.

A partir de tal contextualização, tem-se a seguinte problematização: Quais as percepções dos microempreendedores de Portalegre/RN sobre o contexto em que atuam e as contribuições que oferecem para o Desenvolvimento Local? Como objetivo geral da pesquisa, tem-se: Descrever o contexto em que as microempresas estão operando e os papéis que têm desempenhado para o Desenvolvimento Local de Portalegre/RN, a partir da percepção dos microempreendedores pesquisados.

O trabalho foi estruturado em cinco seções, além desta introdução e das considerações finais. A primeira seção discute as motivações que induzem o empreendedorismo, enfatizando-se aspectos 
relacionados ao cenário brasileiro. $\mathrm{Na}$ seção seguinte apontam-se alguns aspectos sobre as características gerais do empreendedores, salientando-se o papel das inovações e breve descrição do cenário brasileiro. $\mathrm{Na}$ terceira seção são apresentadas algumas considerações sobre a relação do empreendedorismo com o DL. A quarta seção apresenta os procedimentos metodológicos utilizados e traz a caracterização da área de estudo. A quinta seção expõe os resultados e discussões.

\section{Empreendedorismo: motivações e circunstâncias}

A partir da Revolução Industrial, que ocorreu na Inglaterra no século XVIII, o modo de Produção Capitalista (re)configura as estruturas existentes a fim de enfrentar as crises cíclicas e assegurar maiores produtividades e ganhos. Essa característica se acentuou a partir do último quartel do século XX, isso porque os avanços tecnológicos proporcionaram aperfeiçoamentos nas máquinas e equipamentos, garantindo-se produções mais rápidas e custos menores, pari passu, ocorreu um aumento na procura de mão de obra com maior qualificação para atender as necessidades do progresso tecnológico, tornando assim o mercado de trabalho um ambiente ainda mais competitivo (SOUZA et al., 2003).

Nesse contexto, o empreendedorismo, por necessidade, começou a crescer em decorrência do aumento do chamado desemprego tecnológico, restando a abertura de novos negócios como estratégia para obtenção de ocupação e renda para uma parte daqueles que perderam seus postos de trabalho. Saliente-se que o cenário mais competitivo e exigente do mercado de trabalho, em virtude dos avanços tecnológicos, também serviu para a ampliação de oportunidades, especialmente por caracterizar-se num ambiente com economias cada vez mais intensivas na prestação de serviços.

Ademais, não é somente a variável desemprego que pode afetar na escolha de um indivíduo optar por empreender ou não. Fatores pessoais, sociais e econômicos, culturais, políticos etc. podem levar a escolher entre empreender ou buscar inserção no mercado formal de trabalho.

Quando se verifica a existência de um ambiente propício, quando se desfruta de Políticas Públicas facilitadoras ao empreendedorismo, como políticas de apoio à exportação, menores impostos e subsídios, boa infraestrutura para a implementação ou ampliação de novas empresas e facilidades na obtenção de financiamento, ampliam-se, substancialmente, as probabilidades do indivíduo optar por empreender (MENEZES, QUEIROZ, FEIJÓ, 2017).

Nesse sentido, quase todos os governantes, nas três esferas (união, estados e municípios), buscam institucionalizar ações que facilitem a criação, funcionamento e crescimento dos microempreendimentos, posto que reconhecem a relevância de tais negócios para a geração de ocupações e renda para parte substancial da população, servindo, em muitas situações, como a principal forma de garantia de sustento para as famílias dos microempreendedores. Além disso, observa-se também a capacidade de geração de receitas para os cofres públicos, por meio da formalização dos negócios (estratégias como a criação do MEI e do SIMPLES sinalizam a importância de tais negócios como fontes de tributação) e, igualmente, o fato da presença de muitos microempreendimentos tornar o ambiente econômico mais dinâmico, assegurando-se maior circulação de recursos nas localidades que oferecem maior diversidade de serviços e produtos e, por este aspecto, servindo para atender as necessidades dos consumidores locais e como 
atrativo para as populações das áreas próximas, que não desfrutam de opções para a realização de seus desejos.

Por outro lado, quando o mercado oferece salários altos para pessoas qualificadas, os indivíduos com mais anos de escolarização tendem a buscar a integração ao mercado formal de trabalho, evitando os riscos do empreendedorismo (MENEZES, QUEIROZ, FEIJÓ, 2017).

Outro fator que pode servir como indutor para um indivíduo empreender é a idade, fator que pode levar pessoas com idades mais avançadas a se tornarem empreendedoras. Tal situação ocorre justamente porque elas dispõem de mais experiência de mercado e de maiores volumes de capital adquiridos ao longo do tempo, porém deve-se frisar que o empreendedorismo também atrai os jovens, neste caso, por serem menos susceptíveis ao medo de enfrentarem os riscos (MENEZES, QUEIROZ, FEIJÓ, 2017).

Hespanha (2009) aponta fatores que podem levar o indivíduo a empreender: os jovens recém formados ao não obterem um lugar no mercado de trabalho decidem por empreender, muitas vezes oferecendo serviços (de advocacia, engenharia, contabilidade, medicina etc.) e às vezes apoiados pela própria instituição que lhes proporcionaram o diploma; os indivíduos que possuem dificuldades em obter trabalho e pessoas com baixo poder econômico podem optar por empreender, investindo todo seu capital financeiro e material ou, se for o caso, obtendo microcréditos; além desses, tem-se os indivíduos que têm habilidades e experiências profissionais e conhecimento da clientela e que possuem maiores probabilidades de escolherem ser donos de seus próprios negócios.

Segundo Koteski (2004), os principais fatores indutores do microempreendedorismo no Brasil seriam: o aumento da terceirização; o excedente de mão de obra no mercado, devido ao aumento da tecnologia; a tendência a diminuição da taxa de mortalidade e o aumento da taxa de natalidade das empresas de pequeno porte; maior facilidade em enfrentar crises econômicas, devido à necessidade de poucos funcionários, investimentos financeiros baixos, terem uma produção pequena que proporciona que crises não afetem significativamente as suas produções; e devido ao espírito empreendedor ${ }^{4}$ do brasileiro.

Camargo Neto et al. (2017) observaram e fizeram relações entre a escolha em empreender e se tornar empregado, levando em consideração fatores como sexo, raça, escolaridade (ensino superior), aposentadoria e morar no urbano. Neste sentido, estabeleceram as diferenças dos fatores supracitados para as cinco regiões do Brasil (Centro-Oeste, Nordeste, Norte, Sul e Sudeste). Os autores, seguindo dados estabelecidos pelo estudo da Pesquisa Nacional por Amostra de Domicílios (PNAD) de 2014, estipularam uma média entre as cinco regiões do Brasil na escolha de empreender ou ser empregado e concluíram que cerca de $23 \%$ da população optaram por empreender.

Em relação ao gênero, observou-se em todas as regiões e com taxas semelhantes, que o sexo masculino tem maior probabilidade de optar por empreender do que o feminino; em relação à cor, os

\footnotetext{
${ }^{4}$ Segundo estudo realizado pelo Global Entrepreneurship Monitor (GEM) em 31 países para estabelecer o nível de espírito empreendedor da população de cada país, o Brasil ficou entre os dez primeiros colocados, ocupando o $6^{\circ}$ lugar do ranking (KOTESKI, 2004).
} 
autores apontaram que os brancos têm maior probabilidade de se tornarem empreendedores em todas as regiões. Em relação ao grau de escolaridade, a pesquisa mostrou que indivíduos que cursaram o Ensino Superior nas regiões do Norte, Nordeste e Centro-Oeste reduzem a disposição para se tornarem empreendedores. A pesquisa apontou também que pessoas aposentadas no Centro-Oeste, Nordeste, Norte e Sudeste têm maiores chances de optarem por empreender, destacando-se os aposentados do Norte com 23,5\% dos casos; por fim, os autores verificaram que morar na zona urbana diminuiu a escolha por empreender no Sudeste, Sul e Norte; já no Nordeste e Centro-Oeste morar na zona urbana funcionava como estímulo (CAMARGO NETO et al., 2017).

As circunstâncias e motivações variadas que induzem ao empreendedorismo não impedem que se busque a caracterização a partir de alguns traços comuns.

\section{Empreendedorismo: características gerais e o quadro brasileiro}

No caso de microempreendimentos, pode-se admitir que, em linhas gerais, possuem pelo menos uma das seguintes características: pouca inovação em questão de gerência e produção; não empreendem por oportunidade de conquistar maiores lucros, por possuir um mercado propenso e ter habilidades favoráveis, e sim por necessidade, por não conseguirem empregos para suas especialidades profissionais ou qualquer outro que facilite a sua sobrevivência; trabalham com o intuito de minimizar os riscos e têm de forma isolada, um pequeno impacto na economia (HESPANHA, 2009).

O aspecto relacionado à inovação (ou ausência de inovação) tem implicações importantes, isso porque:

Especialmente nos anos recentes, a inovação se tornou um fator determinante da competitividade para todas as organizações, qualquer que seja a sua natureza ou tamanho. Para que pequenas e médias empresas sobrevivam, um objetivo fundamental seria deixar de lado a ideia de que apenas grandes organizações são capazes de conduzir atividades inovadoras (MOMPO, REDOLI, 2009, p. 57 apud BRASIL, NOGUEIRA, FORTE, 2011, p. 46).

De acordo com Vale, Wilkinson, Amâncio (2008), o economista Schumpeter enfatizou que o empreendedorismo afetaria, positivamente, o crescimento econômico a partir da introdução de inovações. Ainda de acordo com os autores, Schumpeter apontou a existência de cinco tipos de inovações que poderiam ser implementadas: a inclusão de um novo produto ou serviço no mercado, inserção de novos métodos de produção, a abertura de um novo mercado, conquistar um novo fornecedor e a instalação de uma nova organização na empresa ou indústria.

Em tal perspectiva, tem-se que os microempreendimentos que conseguem inovar têm maiores possibilidade de êxito, contudo, conforme já salientado, essa possibilidade é limitada, sobretudo pela escassez de recursos, constituindo-se numa verdadeira armadilha: é micro, portanto não consegue inovar e sem inovação dificilmente consegue deixar a condição de micro. 
Neste sentido, a principal possibilidade para superação de tal barreira repousa no ambiente externo ${ }^{5}$, como, por exemplo, na Finlândia. Em tal país verificou-se que o bom desempenho do segmento se deu em decorrência de Políticas Públicas desenhadas para o atendimento das carências existentes, em que as autoridades tiveram a preocupação de envolver centros educacionais capazes de desenvolver inovações tecnológicas apropriadas as demandas do segmento; desenvolvimento de métodos de melhor utilização de matérias primas, priorizando-se o uso de recursos renováveis; além de proporcionar melhorias de trabalho e bem estar para os trabalhadores; enfim, criando-se um ambiente condizente para as empresas atuantes e atrativo para outros empreendedores que desejassem se estabelecer (VILLASCHI, 2003).

Em relação ao cenário brasileiro, especialmente a partir da abertura comercial que se processou na década de 1990, tornou-se cada vez mais desafiador para as empresas estabelecidas no país, isso porque ocorreu uma avalanche de produtos importados invadindo o mercado que, até então, era relativamente protegido e atendido por empresas instaladas no país. Os preços baixos dos importados afetaram negativamente as empresas, porquanto elas não tiveram o tempo necessário para se adaptarem e muitas não conseguiram produzir com custos baixos e preços competitivos, comparativamente aos produtos importados. Devido a isso, as indústrias brasileiras, ao venderem menos, começaram a cortar seus custos, principalmente por intermédio da diminuição dos quadros de funcionários, incorrendo-se, por implicação, no aumento do desemprego (SOUZA et al., 2003).

$\mathrm{O}$ aumento do desemprego, muito provavelmente, contribuiu para o aumento do empreendedorismo por necessidade, especialmente no mercado informal. Tal aspecto pode ser relacionado ao fato de grande parte dos empreendimentos terem começado com pouco capital, sendo que a formalização dos negócios exigia aportes de recursos que a grande maioria não dispunha (SOUZA et al., 2003).

Noutras palavras, a abertura econômica promovida unilateralmente pelo governo brasileiro, acompanhada por uma crise que se arrastava desde o início da década de 1980, comprometeu ainda mais o mercado de trabalho e o empreendedorismo se tornou uma forma possível para milhares de brasileiros obterem alguma renda, mesmo com o mercado consumidor estando também fragilizado, devido a esse contexto econômico que o país enfrentava (SOUZA et al., 2003).

Em relação à instituição de medidas de fomento para o segmento empreendedor de micro e pequenas dimensões no Brasil, pode-se citar a criação, em 1999, do Programa Brasil Empreendedor, que tinha como objetivo facilitar o fornecimento de créditos das instituições de financiamento para os empreendedores e proporcionar-lhes oportunidades para se capacitarem em gestão, educação financeira e acesso a serviços de consultorias, de forma a assegurar a sobrevivência e a ampliação da rentabilidade dos

\footnotetext{
${ }^{5}$ Países como a Itália, Japão e Reino Unido também tiveram bons resultados a partir do apoio do Poder Público, em que políticas específicas para os micro e pequenos empreendimentos proporcionaram treinamentos; estímulos para a criação de novas tecnologias, apoiando as instituições de pesquisa; apoio ao acesso rápido de inovações disponíveis no mercado; dentre outras iniciativas (SOUZA et al., 2003).
} 
negócios. A leitura das autoridades governamentais da época era que a principal dificuldade das empresas seria o elevado índice de mortalidade 6 (DORNELAS, 2008).

Saliente-se que um importante aliado do empreendedor brasileiro é o Serviço de Apoio às Micro e Pequenas Empresas (SEBRAE), que tem como principal objetivo fortalecer a competitividade e sustentabilidade dos pequenos negócios, além de proporcionar consultoria e orientações de produção, financeira e estudo da concorrência e clientela para quem já tem o próprio negócio ou que esteja pensando em abrir (SEBRAE, 2018).

Reconhece-se que o empreendedorismo tem impactos econômicos positivos e se faz necessário descrever o papel que desempenha para o Desenvolvimento Local. Ademais, verifica-se a partir da produção acadêmica crescente sobre a temática, que diversas estratégias podem ser adotadas por empreendedores, microempreendedores, agentes públicos, entidades do terceiro setor nas diferentes nações, regiões e localidades, mediante utilização de estratégias de adaptações às particularidades e do enfrentamento das adversidades que ainda prevalecem no cenário econômico.

\section{Empreendedorismo e desenvolvimento local: breves considerações}

Almeida, Sediyama, Santiago (2017) fizeram um estudo com o objetivo de estabelecer a relação do empreendedorismo com o Produto Interno Bruto (PIB) das regiões do Brasil, e salientaram que as regiões têm diferentes culturas e desigualdades, tanto sociais como econômicas. Observaram que em todas as regiões brasileiras existe uma relação positiva entre o empreendedorismo e o crescimento econômico, até mesmo em estados com menores dinamismos econômicos foi estabelecida essa relação, destacando-se Goiás, Rio Grande do Norte, Sergipe, Pernambuco, Paraíba e Ceará.

Souza et al. (2016, p. 262-3), tendo o estado de Minas Gerais como área de estudo, apresentaram

[...] um panorama do Microempreendedor Individual - MEI -, de forma a analisar os benefícios e a efetividade deste programa, enquanto política pública para a criação de novos empreendimentos, formalização de empreendimentos informais, melhorias no desempenho dos pequenos negócios e promoção do desenvolvimento local. [De acordo com os autores] Os resultados identificaram correlações positivas entre os optantes pelo programa MEI com os níveis de renda e índice de desenvolvimento municipal, além de correlação negativa com os níveis de desemprego.

Percebe-se que para a obtenção de melhores resultados na redução das desigualdades sociais e econômicas, constituem-se em elementos essenciais: a cooperação entre as empresas, uma boa relação entre os organismos e instituições constituídas no território, simultaneamente, com uma maior participação dos atores sociais (MULS, 2008).

Além dos aspectos salientados por Muls (2008), percebe-se que as instituições governamentais, não governamentais e empresariais devem proporcionar um ambiente favorável ao desenvolvimento, mas

\footnotetext{
${ }^{6}$ Tal circunstância é devido à falta de planejamento dos empreendedores, por não terem um estudo prévio do mercado (englobando o mercado fornecedor, concorrente e consumidor) em que desejam atuar e por não dimensionarem adequadamente as dificuldades para incorporarem inovações (DORNELAS, 2008).
} 
para tanto devem ter um conhecimento adequado das dinâmicas econômicas existentes. A partir dos diagnósticos realizados é desejável que sejam instituídos programas e projetos voltados ao empreendedorismo, buscando-se aproveitar os distintos recursos disponíveis nas localidades; isso porque tais iniciativas são de extrema importância para que as empresas encontrem um local atrativo para a realização dos investimentos. Saliente-se que a instituição e a execução das iniciativas governamentais devem contar com a participação dos segmentos não governamentais e empresariais em todas as etapas.

Observa-se que:

[...] qualquer estratégia para promoção do desenvolvimento local deve se estruturar em, pelo menos, três grandes pilares: organização da sociedade, contribuindo para a formação de capital social local (entendimento como capacidade de organização e cooperação da sociedade local) combinada com a formação de espaços institucionais de negociação e gestão, agregação de valor na cadeia produtiva, com a articulação e o aumento da competitividade das atividades econômicas com vantagens locais, e reestruturação e modernização do setor público local, como forma de descentralização das decisões e elevação de eficiência e eficácia da gestão pública local (BUARQUE, 2008, p. 27). (Grifos dos autores).

Mesmo que a localidade seja dependente economicamente de estruturas externas deve trabalhar com estratégias que modifiquem o ambiente interno, pois ao esperar somente por medidas vindas de fora ampliam-se os condicionantes para que não se concretizem mudanças na estrutura. Assim, para se promoverem alterações, deve-se levar em consideração a capacidade dos atores sociais, isso porque: “[...] o desenvolvimento local depende, portanto, da capacidade dos atores locais de compreender esses processos e responder, de forma apropriada, com suas próprias forças e talentos, num processo permanente de aprendizagem.” (BUARQUE, 2008, p. 31).

$\mathrm{Na}$ literatura observa-se a relevância atribuída à mobilização dos atores locais para o estabelecimento de laços de confiança, criação e manutenção de um ambiente propício, contando com a participação do Poder Público para a implementação de melhorias produtivas para ampliação da competitividade. Além disso, aponta-se o necessário protagonismo dos atores sociais como o caminho mais satisfatório para a mitigação dos problemas existentes e para potenciação dos elementos endógenos favoráveis existentes nas localidades.

Saliente-se que tais atributos, embora indispensáveis, não são suficientes para a promoção do DL. Verificam-se as necessárias "reestruturação" e "modernização" do Setor Público local para que a atuação institucional seja capaz de fomentar o potencial empresarial existente nas distintas localidades. Ou seja, os requisitos necessários para que o processo de DL se estabeleça tem que considerar a existência dos seguintes pilares: organização da sociedade, agregação de valor na cadeia produtiva e reestruturação e modernização do Setor Público local.

\section{Procedimentos metodológicos e caracterização da área de estudo}

O estudo utilizou-se da pesquisa descritiva, cujo propósito é descrever a particularidade de uma população (GIL, 2010). Quanto à sua natureza, a pesquisa é classificada como quali-quantitativa. Para o 
alcance do objetivo estabelecido (descrever o contexto em que as microempresas estão operando e os papéis que têm desempenhado para o Desenvolvimento Local de Portalegre/RN, a partir da percepção dos microempreendedores pesquisados) foram realizadas pesquisas bibliográfica e de campo, além de levantamento de dados em sites, como o do IBGE.

$\mathrm{Na}$ pesquisa de campo foram realizadas entrevistas com microempreendedores e com o responsável pela Sala do Empreendedor do município. Para definição da amostra, tomou-se por base o número de negócios cadastrados na Junta Comercial do município. Apurou-se que, em 2019, existiam 293 microempresas com Alvarás de Licenciamento expedidos, sendo 162 microempresas formalizadas.

O primeiro critério foi selecionar microempreendedores formalizados e com Alvará de Licenciamento expedido pelo município (162 microempresas); em face de tal cenário, definiu-se uma amostra de 15\% como bem representativa, chegando-se à quantidade de 25 microempreendedores. Para que se pudesse captar distintas percepções sobre o contexto em que atuam e sobre os papéis que entendem desempenhar para o DL, segmentou-se a amostra definida, estabelecendo-se 10 entrevistados com atuação há até 10 anos no mercado portalegrense e 15 com atuação há mais de 10 anos, priorizandose uma maior representação daqueles que conseguiram uma posição mais consolidada no mercado local.

A pesquisa de campo foi realizada no período de fevereiro a abril de 2019 e teve como área de estudo a zona urbana de Portalegre/RN. As técnicas utilizadas nessa etapa foram a observação direta do cenário econômico portalegrense, mediante visitas aos pontos de reconhecida movimentação comercial para a coleta de informações, bem como a realização de entrevistas semiestruturadas com os microempreendedores e o servidor público responsável pela Sala do Empreendedor do município.

De acordo com o IBGE (2010), Portalegre é um município do Rio Grande do Norte, localizado na Região Geográfica Imediata de Pau dos Ferros, situando-se a uma distância de 373,6 km (via BR-304) da capital do estado, Natal.

De acordo com dados coletados no último recenseamento populacional, IBGE (2010), o município contava com 7.320 habitantes, com 3.843 residentes na zona urbana e 3.477 na zona rural, apresentando uma densidade geográfica de $66,51 \mathrm{hab} . / \mathrm{km}^{2}$ e uma área territorial de $110,054 \mathrm{~km}^{2}$; limita-se geograficamente com os municípios de Taboleiro Grande/RN, Riacho da Cruz/RN, Viçosa/RN, Martins/RN, Serrinha dos Pintos/RN e Francisco Dantas/RN, ver Figura 1. 
Figura 1 - Localização e limites geográficos do município de Portalegre/RN

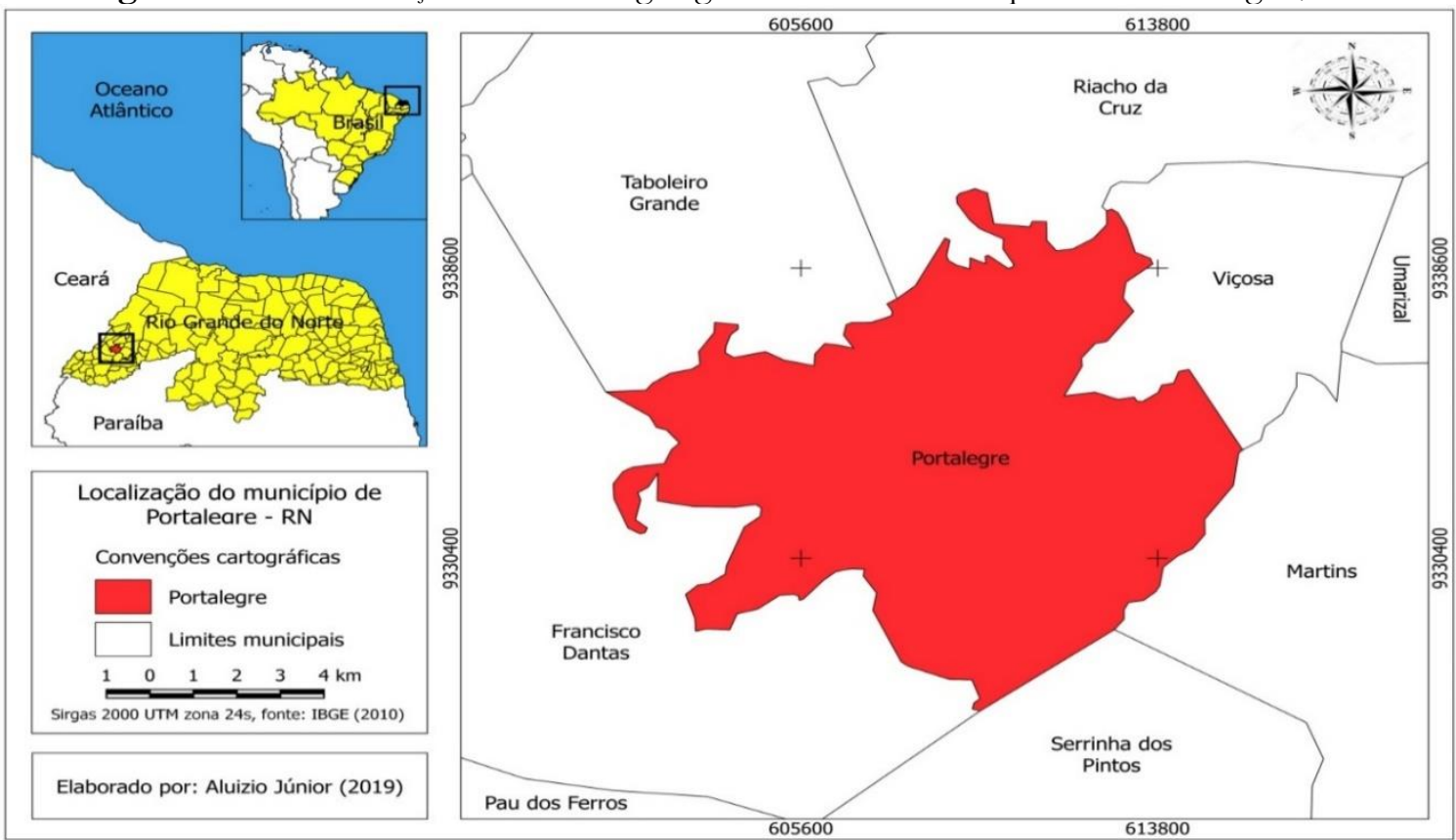

Fonte: Base cartográfica, IBGE (2010). Elaborado por Bezerra Junior (2019).

Sobre a economia do município, sabe-se que:

Tem sua base econômica muito dependente do Setor Público (servidores públicos e transferências diretas a população), apresenta um setor comercial e de serviços com a presença predominante de micro e pequenas empresas, sendo muito forte a presença de informais, dispõe de alguns poucos pontos turísticos que servem, prioritariamente, ao turista da região e uma agricultura em franca decadência.

A zona rural de Portalegre tem a cajucultura como principal atividade produtiva, mas as evidências indicam que as famílias residentes nos minifúndios se dedicam a variadas atividades, muitas delas não agrícolas, destacando-se a presença de muitos aposentados e pensionistas nas famílias (BARRETO FILHO, OLIVEIRA, 2016, s/p).

De acordo com o IBGE (2016), o município possui um PIB per capita de R \$ 6.873,73. Destaque-se ainda que o município de Portalegre/RN conta com belas paisagens, principalmente nas áreas em que ainda se observam resquícios de mata, algumas formações rochosas e cachoeiras, apresentando ao longo do ano uma temperatura bem mais agradável do que a existente no sertão, sendo que tais atributos serviram para fomentar a atividade turística, ainda que, preponderantemente, servindo para atração de turistas da Região Geográfica Intermediária de Mossoró.

A partir dos diferenciais associados ao ambiente natural, verifica-se que micro e pequenos empreendedores passaram a tirar proveito e optaram por atuar no setor de hospedagem, restaurantes e bares, mas contando também com empreendimentos de serviços diversos, como laboratórios, salões de beleza (cabeleireiros, manicures), escritórios de advocacia, além de estabelecimentos comerciais voltados ao setor agrícola, vestuário e calçados, mercados e mercearias, dentre outros. 


\section{Resultados e discussões}

Com o estudo empreendido, verificou-se que ainda existem muitos estabelecimentos que atuam na informalidade e, tomando-se como base o cadastro existente na Junta Comercial do município, constatou-se que, em 2019, das 293 microempresas com Alvará de Licenciamento expedido pela Prefeitura, somente cerca de 55,3\% dessas estavam formalizadas.

Apurou-se que o incentivo à formalização viabilizado pela proposta de Microempreendedor Individual (MEI), está surtindo efeitos positivos, pois 56\% dos entrevistados formalizados, 78,6\% constituem-se como MEI. Também foi constatado que o SEBRAE exerce papel importante no apoio aos microempreendimentos, seja com incentivos a abertura de novos estabelecimentos, ou proporcionando cursos e orientações para que melhorem as estratégias de atuação no mercado.

Conforme as informações do Gráfico 1, percebem-se resultados razoáveis no nível de escolaridade, com 64\% dos microempreendedores tendo o Ensino Médio completo ou mais anos de estudo. Todos os entrevistados frequentaram o ambiente escolar, nem que fosse por um curto prazo. Entre os microempreendedores pesquisados 36\% cursaram o Ensino Médio completo, 8\% já possuem diploma universitário e 20\% possuem o Ensino Superior incompleto. Entre os demais, 16\% indicaram o Ensino Fundamental completo e 12\% incompleto, e, por fim, 8\% possuem Ensino Médio incompleto.

Gráfico 1 - Nível de escolaridade dos microempreendedores de Portalegre/RN

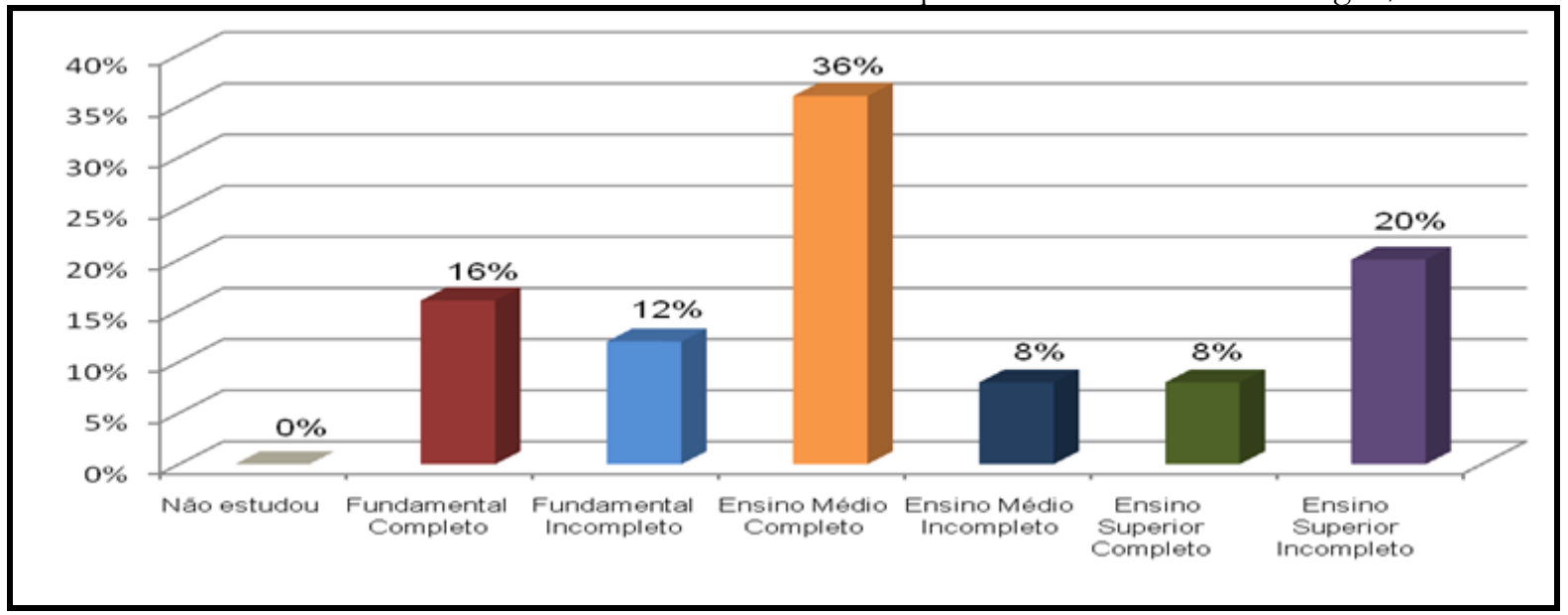

Fonte: Elaboração própria. Pesquisa de Campo (2019).

De acordo com o Gráfico 2, a renda gerada por meio dos microempreendimentos representa um papel muito representativo para o sustento familiar. Observa-se que somente $12 \%$ não possuem nenhuma pessoa dependente financeiramente do negócio. Estimulando os entrevistados sobre a relevância do negócio para o sustento familiar, observou-se declarações como a seguinte: “acabo ajudando todos daqui de casa com o dinheiro que arrecado, até mesmo os que já possuem emprego." (MICROEMPREENDEDOR 1, PESQUISA DE CAMPO, 2019).

Em geral, as falas indicaram que, apesar de modesta, a geração de renda proveniente dos microempreendimentos teria muita representatividade na composição do orçamento familiar, sendo 
apontado pelos entrevistados que $32 \%$ teriam quatro ou mais dependentes, $24 \%$ teriam dois dependentes e 20\% teriam três dependentes financeiros dos negócios.

Gráfico 2 - Pessoas dependentes financeiramente dos microempreendendores de Portalegre/RN

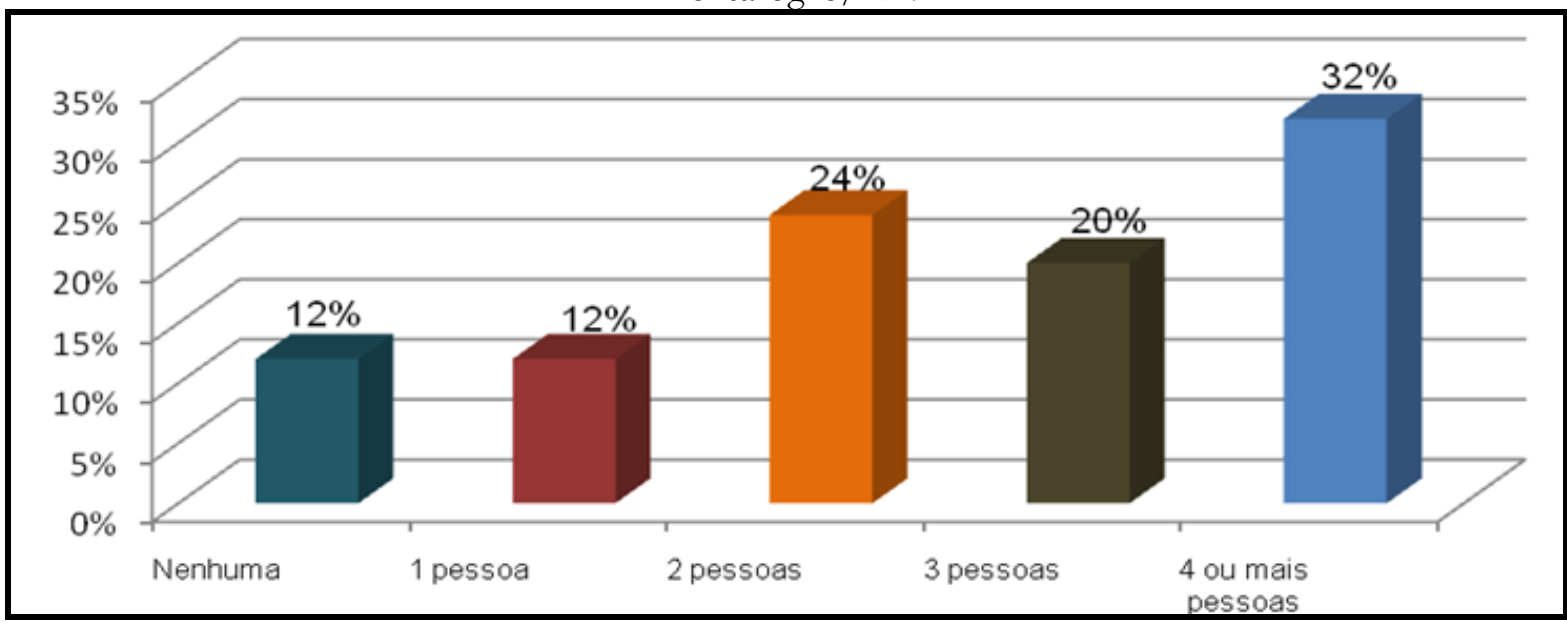

Fonte: Elaboração própria. Pesquisa de Campo (2019).

Constatou-se que, na maioria dos casos, as microempresas pesquisadas estão sendo comandadas por mulheres ${ }^{7}(56 \%)$, por pessoas casadas e/ou com relação estável (52\%), possuidores de Ensino Médio completo e/ou mais anos de estudo (64\%), indivíduos de cor $^{8}$ branca $(56 \%)$, com faixa etária ${ }^{9}$ predominante de 25 até 45 anos (64\%) e que possuem somente o microempreendimento como fonte de renda própria e da família $(68 \%)^{10}$.

Quando os pesquisados foram estimulados ${ }^{11}$ para hierarquizar as vantagens existentes na constituição do segmento das microempresas locais, observaram-se as seguintes recorrências nas respostas: possibilidade de gerenciar o horário de trabalho; ter retorno do investimento, mesmo que seja modesto; poder alcançar o crescimento pessoal administrando a própria empresa e; facilidades na obtenção de crédito.

Em relação aos problemas enfrentados pela economia brasileira (desemprego crescente, diminuição da atividade econômica, dificuldades fiscais, sobretudo nos municípios com bases produtivas mais modestas etc.) foi relatado, por $100 \%$ dos microempreendedores, que tais problemas econômicos

\footnotetext{
7 Camargo Neto et al. (2017) observaram que em todas as regiões brasileiras o sexo masculino possuía maior probabilidade de se tornar empreendedor.

${ }^{8}$ Pardos: $32 \%$; Negros: $8 \%$ e Indígenas: $4 \%$.

${ }^{9}$ Até 24 anos: 4\%; acima de 45 anos: 32\%. Em relação à faixa etária Menezes, Queiroz e Feijó (2017) observaram que pessoas entre 35 a 40 anos têm maior atratividade em tornarem-se empreendedoras, devido ao acúmulo de capital financeiro e experiência de mercado.

${ }^{10}$ Os demais declararam possuir renda complementar de alguma das seguintes fontes: da agricultura, por atuar em empresa privada, ser funcionário público, possuir outro empreendimento, receber programa de auxílio do governo (Bolsa Família). Os 32\% que informaram disporem de rendas complementares indicaram os montantes de tais rendas: $25 \%$ responderam receber menos de 1 salário mínimo; $50 \%$ indicaram que recebem 1 salário mínimo e 25\% indicaram que recebem mais de 1 até 2 salários mínimos.

${ }^{11}$ Foi pedido aos microempreendedores que apresentassem, em ordem de importância, as vantagens em dispor de uma microempresa no mercado local.
} 
também estão impactando negativamente os negócios, contudo foi destacado por parte dos entrevistados, aproximando-se da constatação de Koteski (2004), que as microempresas têm mais facilidades para enfrentarem uma crise, principalmente por não possuírem funcionários e não necessitarem adquirir grandes quantidades de produtos.

Ainda sobre o contexto econômico recente, cerca de $44 \%$ destacaram que o faturamento no começo de 2019 se manteve quando comparado ao mesmo período do ano passado (de janeiro até abril), $28 \%$ declararam que diminuiu, $16 \%$ declararam que aumentou e $12 \%$ não souberam ou não quiseram informar.

Ademais, os microempreendedores entrevistados demonstraram otimismo em relação ao desempenho do negócio no ano de 2019: 72\% acreditam em crescimento dos negócios, 24\% indicaram a manutenção, enquanto que um entrevistado (4\%) acredita que encerará as atividades no ano em curso.

Todos os micrempreendedores entrevistados acreditam que suas empresas têm impactos positivos no processo de Desenvolvimento Local de Portalegre/RN. Quando estimulados a relatarem as formas de impactos que consideram mais importantes para o DL foram salientadas as seguintes respostas: geração de ocupações e renda; garantia de sustento para as familias dos microempreendedores; geração de receitas para os cofres públicos; facilitação da vida dos consumidores; circulação de recursos na economia da cidade.

Não foram observadas referências ao estabelecimento de parcerias e/ou quaisquer tipos de laços entre os entrevistados, nem sobre a existência de algum tipo de articulação, ainda que informal, entre os microempreendedores.

Questionados sobre apoios e/ou carências relacionadas a atuação do Poder Público foram observadas as seguintes respostas: a maioria dos microempreendendores classificou os incentivos do Governos Federal e Estadual ao empreendedor como ruins ou péssimos, salientando as exigências burocráticas e a excessiva tributação como os principais problemas decorrentes da ação estatal.

No que se refere ao Poder Público municipal, a maioria não soube informar sobre os incentivos disponibilizados para o apoio ao microempreendedor, mas existiram alguns relatos sobre participação em cursos do SEBRAE realizados em parceria com a Prefeitura Municipal. Saliente-se a seguinte declaração: "não posso falar que não temos apoio em relação ao Poder Municipal, pois já participei de cursos aqui na cidade que era destinados aos empreendedores." (MICROEMPREENDEDOR 5, PESQUISA DE CAMPO, 2019).

Foi verificado que o município conta, desde 2014, com a 'Sala do Empreendedor', sendo que a estruturação do ambiente decorreu de uma parceria entre a Prefeitura Municipal de Portalegre/RN e o SEBRAE. A 'Sala', segundo apurado, tem como propósito oferecer facilidades para a regularização (formalização) das atividades e prestar esclarecimentos sobre obtenção de crédito e existência de cursos para aperfeiçoamento dos empreendedores. (RESPONSÁVEL PELA SALA DO EMPREENDEDOR, PESQUISA DE CAMPO, 2019). 
Ainda sobre os serviços prestados ao público:

\begin{abstract}
Destacamos sempre a importância deste espaço para um melhor atendimento e qualidade da indústria, comércio e sociedade em geral, uma vez que pode fomentar o desenvolvimento, o fortalecimento dos empreendimentos de pequeno, médio e grande porte. A Sala conta com informações e orientações sobre abertura, funcionamento e formalização de empresas. Além disso, a Sala oferece atendimento presencial individual, orientação de controle [de estoques], [fluxo de] caixa e vendas, palestras e orientações sobre direitos e obrigações. (RESPONSÁVEL PELA SALA DO EMPREENDEDOR, PESQUISA DE CAMPO, 2019).
\end{abstract}

Nota-se que o Poder Municipal observou a relevância dos microempreendedores do município e criou a 'Sala do Empreendedor' como forma de apoiá-los, além de objetivar o fortalecimento das empresas já firmadas e atrair a abertura de novas. De acordo com um entrevistado: "se o município não desse apoio a abertura de novas empresas, creio que não teria acontecido esse aumento de novas empresas que notamos.” (MICROEMPREENDEDOR 6, PESQUISA DE CAMPO, 2019).

Em relação aos microempreendedores com menor tempo de mercado (até 10 anos), quando questionados sobre o principal incentivo que levaram a empreender, cerca de $27 \%$ responderam que foi para incrementar a renda familiar, outros $27 \%$ indicaram a falta de oportunidade de obter um trabalho assalariado, assentando-se que 54\% não empreenderam por oportunidade. Pode-se notar que o resultado observado se compatibiliza com o trabalho de Hespanha (2009), em que empreendimentos com menores dimensões não seriam impulsionados pelo mercado favorável, mas por necessidade e por não ter facilidade na obtenção de outra ocupação no mercado formal de trabalho.

Entre os empreendedores com mais de 10 anos de atuação, a maioria optou por empreender por outros motivos: 30\% empreenderam com o objetivo de não ter um chefe e possuir sua própria empresa, $20 \%$ agarraram uma oportunidade de negócio e 10\% queriam potencializar um dom. Os que empreenderam por necessidade: 30\% afirmaram que queriam incrementar a renda familiar e $10 \%$ pela dificuldade de encontrar um trabalho assalariado.

Algo importante a ser destacado foi a questão do local de funcionamento das empresas. Foi constatado que o grupo empresarial que está constituído no mercado há mais tempo, 80\% trabalham em local próprio e 20\% ficam divididos, igualmente, para estabelecimentos alugados e cedidos. Resultado diferenciado foi averiguado no outro grupo de entrevistados (com até 10 anos de atuação): 40\% declararam que os negócios funcionam em estabelecimentos próprios, 47\% em estabelecimentos alugados e $13 \%$ em estabelecimentos cedidos.

\title{
Considerações finais
}

Considera-se que o ambiente institucional, nos termos propostos por Menezes, Queiroz, Feijó (2017), não atendeu às expectativas dos microempreendedores pesquisados, posto que ressaltaram a insuficiência/inexistência de apoios dos Governos Federal e Estadual e a modesta atuação do Governo Municipal, cuja ação mais evidenciada foi a criação, em parceria com o SEBRAE, da 'Sala do Empreendedor'. Nesse sentido, em linhas gerais, a percepção dos entrevistados sobre a atuação do Poder 
Público não sinalizou para o estabelecimento a geração de medidas facilitadoras, tampouco a existência de um ambiente favorável à criação e expansão dos microempreendimentos.

Ressalve-se que as percepções dos entrevistados sobre a insuficiência/inexistência de apoios da esfera federal contrasta com dados apurados na pesquisa sobre o aumento da formalização dos negócios por intermédio do MEI, aspecto que sugere a possibilidade do desconhecimento sobre a responsabilidade do Governos Federal pela instituição da medida.

Também ficou patente que o ambiente prevalecente entre os microempreendedores é de ausência de colaboração, predominando a concorrência, e sem perspectivas para mudanças de atitudes, ao menos num curto prazo, constituindo-se numa circunstância limitadora, tendo em vista que a mobilização e a participação ativa dos atores são importantes instrumentos para potenciar o DL.

A pesquisa de campo evidenciou que, grande parte dos microempreendedores, além de só possuírem seus estabelecimentos como fonte de renda, tem seus microempreendimentos comandados por núcleos familiares, desempenhando papel significativo para o sustento dos parentes, demonstrando-se a importância como fonte geradora de renda e de ocupações na localidade, mas com pouca capacidade de incorporar inovações e/ou ampliar a rentabilidade dos negócios mediante agregação de valor aos produtos comercializados e serviços prestados.

Quando cotejados com os pilares do DL se observa que os microempreendimentos não dispõem dos requisitos necessários para que o processo se estabeleça, contudo, apurou-se que $100 \%$ dos entrevistados consideraram seus estabelecimentos relevantes para o Desenvolvimento Local.

Para tanto, faz-se necessário que os microempreendimentos existentes em Portalegre/RN disponham de maior atenção por parte das autoridades constituídas, bem como que ocorra o estabelecimento de laços e parcerias como forma de ampliar o poder de pressão para a conquista de melhorias e de resultados econômicos mais propícios ao segmento. Em tal mudança é indispensável levar em consideração o papel que o microempreendedorismo tem no Desenvolvimento Local e cabe aos agentes, sobretudo governamentais, criarem ou potencializarem as oportunidades para a realização de investimentos privados, para introduzir/ampliar as inovações, enfim, para tornar o ambiente propício para o crescimento das microempresas existentes e para a atração de novos negócios.

Acrescente-se que a geração de informações sobre o microempreendedorismo em Portalegre/RN apresenta limitações, mas pode ser útil para os microempreendedores estabelecidos ou interessados em criarem novos negócios, mediante avaliação das condições existentes e das possíveis estratégias para ampliação ou implantação das empresas. Nessa perspectiva, destaca-se que as discussões apresentadas abrem espaço para novos olhares e aprofundamentos por parte de pesquisadores que tenham interesse nessa área.

\section{Referências}

ALMEIDA, Fernanda Maria de; SEDIYAMA, Gislaine Aparecida Santana; SANTIAGO, Felipe Afonso. A Contribuição do Empreendedorismo para o Crescimento Econômico dos Estados Brasileiros.

REGEPE-Revista de Empreendedorismo e Gestão de Pequenas Empresas, v. 6, n. 3, p. 466-494, 2017. 
BAGGIO, Adelar Francisco; BAGGIO, Daniel Knebel. Empreendedorismo: Conceitos e definições. Revista de empreendedorismo, inovação e tecnologia, v. 1, n. 1, p. 25-38, 2015.

BARRETO FILHO, Boanerges de Freitas; OLIVEIRA, Maria Kalina de Souza. O PRONAF na Comunidade Quilombola "Negros Felicianos do Alto" de Portalegre/RN. Anais XI SOBER NORDESTE. 2016.

BRASIL, Marcus Vinicius de oliveira; NOGUEIRA, Cláudio André Gondim; FORTE, Sérgio Henrique Arruda Cavalcante. Schumpeter e o desenvolvimento tecnológico: uma visão aplicada às pequenas e médias empresas. Revista de ciências da administração, v. 13, n. 29, p. 38-62, 2011.

BUARQUE, Sérgio José Cavalcanti. Construindo o desenvolvimento local sustentável: metodologia de planejamento. 4 ed. Rio de Janeiro: Garamond, 2008.

CAMARGO NETO, Roque Pinto de et al. Condicionantes do empreendedorismo no Brasil: uma abordagem regional. Revista Brasileira de Estudos Regionais e Urbanos (RBERU) vol. 11, n. 4, p. 447-466, 2017.

DORNELAS, José Carlos Assis. Empreendedorismo: transformando idéias em negócios. Rio de Janeiro: Campus, 2005.

GIL, Antonio Carlos. Como elaborar projetos de pesquisa. 5. ed. São Paulo: Atlas S.A., 2010.

HESPANHA, Pedro. Microempreendedorismo. Dicionário internacional da outra economia, p. 248254, 2009.

IBGE. Cidades, 2010. Disponível: < $<$ https://cidades.ibge.gov.br/brasil/rn/portalegre / panorama $>$. Acesso em: 09 nov. 2018.

KOTESKI, Marcos Antonio. As micro e pequenas empresas no contexto econômico brasileiro. Revista FAE Business, v. 8, n. 1, p. 16-18, 2004.

MARTINS, Sérgio Ricardo Oliveira. Desenvolvimento Local: questões conceituais e metodológicas. Revista Internacional de Desenvolvimento Local. Vol. 3, N. 5, p. 51-59, set. 2002.

MENEZES, Gabrielito; QUEIROZ, Vivian dos Santos; FEIJÓ, Flávio Tosi. Determinantes do empreendedorismo no Brasil: uma análise da escolha ocupacional e dos rendimentos. Revista Brasileira de Estudos Regionais e Urbanos (RBERU). Vol. 11, n. 4, pp. 447-466, 2017.

MULS, Leonardo M. Desenvolvimento local, espaço e território: o conceito de capital social e a importância da formação de redes entre organismos e instituições locais. Revista EconomiA, Brasília, v. 9, n. 1, p. 1-21, 2008.

SEBRAE. Portal do SEBRAE. O que Fazemos. Disponível em: < http://www.sebrae .com .br/sites/PortalSebrae/canais adicionais/o que fazemos >. Acesso em: 22 jun. 2019.

SOUZA, Donizeti Leandro de et al. Empreendedorismo e desenvolvimento local: uma análise do programa microempreendedor individual em Minas Gerais, Brasil. Desenvolvimento em Questão, v. 14, n. 37, p. 262-292, 2016.

SOUZA, Maria Carolina de Azevedo Ferreira de et al. Perspectivas para uma atuação competitiva das pequenas empresas no contexto econômico atual. In: LASTRES, Helena Maria Martins; CASSIOLATO, José Eduardo; MACIEL, Maria Lucia. Pequena empresa: cooperação e desenvolvimento local. Rio de Janeiro: Relume Dumará, 2003. 
SWINBURN, Gwen; GOGA, Soraya; MURPHY, Fergus. Desenvolvimento Econômico: um manual para a implementação de estratégias para o desenvolvimento econômico local e planos de ação, 2006.

VALE, Gláucia Maria Vasconcellos; CORRÊA, Victor Silva; REIS, Renato Francisco dos. Motivações para o empreendedorismo: necessidade versus oportunidade?. RAC-Revista de Administração

Contemporânea, v. 18, n. 3, p. 311-327, 2014.

VILLASCHI, Arlindo. Competitividade Finlandesa e fomento a pequenas e médias empresas: raízes históricas para sucessos no presente. In: LASTRES, Helena Maria M.; CASSIOLATO, José Eduardo; MACIEL, Maria Lucia (Orgs.). Pequena empresa: cooperação e desenvolvimento local. Rio de Janeiro: Relume Dumará, 2003. 